\title{
Hemiparesis of bladder caused by tethered cord
}

\author{
Ryan A. Payne, MD; R. Corey O'Connor, MD; Michael L. Guralnick, MD
}

\section{Abstract}

Conventional teaching has maintained that the detrusor musculature is wellcoupled and unilateral innervation should prompt a coordinated detrusor contraction. We present the case of a 17-year-old girl with a tethered spinal cord, unilateral neurologic symptoms and fluoroscopic evidence of ipsilateral hemiparesis of the bladder unresponsive to cord detethering. This adds to a small body of evidence that the bladder smooth muscle is less well-coupled than once believed.

CUAJ 2008;2(1):55-6

\section{Introduction}

The literature describes interconnectivity or coupling between detrusor smooth muscle cells during contraction. ${ }^{1,2}$ However, there is contradicting evidence that detrusor smooth muscle fibres are less wellcoupled than other smooth muscle cells in the body. ${ }^{3,4}$ In addition, there is a paucity of information regarding the effect of unilateral neurologic input on detrusor contractions. Our case report describes a patient with unilateral neurologic symptoms from a tethered spinal cord and corresponding video-urodynamic evidence of ipsilateral hemiparesis of the bladder.

\section{Case report}

A 17-year-old girl presented to the neurosurgical service with a 2-year history of progressive weakness and atrophy of the right lower extremity, right-sided back pain and right gluteal numbness. She denied motor or sensory changes on the left side. Magnetic resonance imaging (MRI) of her spine revealed spina bifida occulta and a tethered spinal cord in the sacral spinal canal. She had mild lower urinary tract symptoms consisting of occasional mild hesitancy and intermittency. She experienced 1 symptomatic lower urinary tract infection while pregnant. There was no history of abdominal or pelvic surgery, or trauma. She was scheduled for neurosurgical intervention and underwent video urodynamic studies (VUDS) as part of her preoperative workup. VUDS revealed low amplitude detrusor overactivity to $18 \mathrm{~cm} \mathrm{H}_{2} \mathrm{O}$ without incontinence at $125 \mathrm{~mL}$ instilled, mildly elevated voiding pressure (detrusor

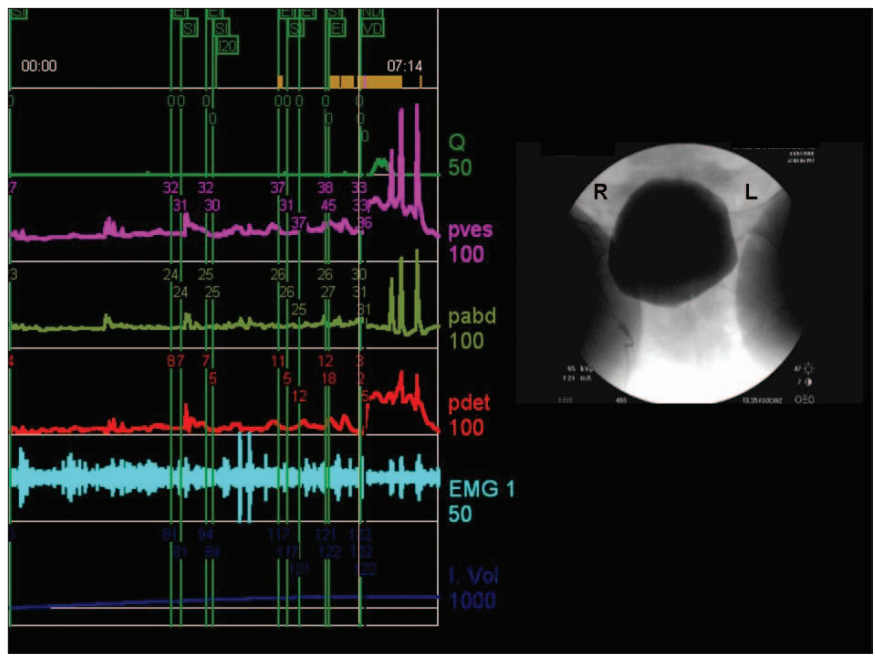

Fig. 1. Video urodynamic study tracing imagery showing low amplitude detrusor overactivity and fluoroscopic appearance before voiding.

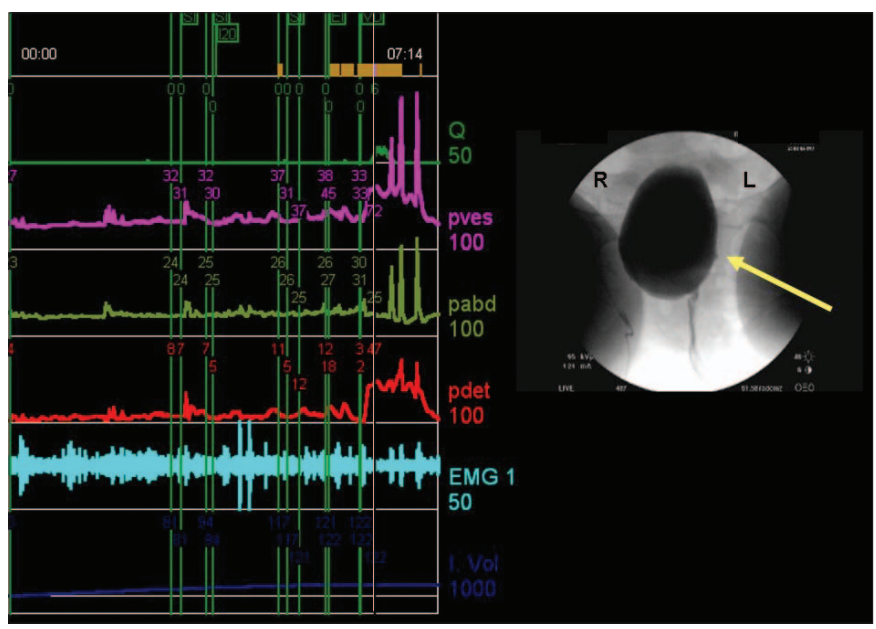

Fig. 2. Video urodynamic study tracing and imagery showing a unilateral voiding bladder contraction and the area (arrow) of detrusor contractility (i.e., the left wall of the bladder deviating toward the midline). 


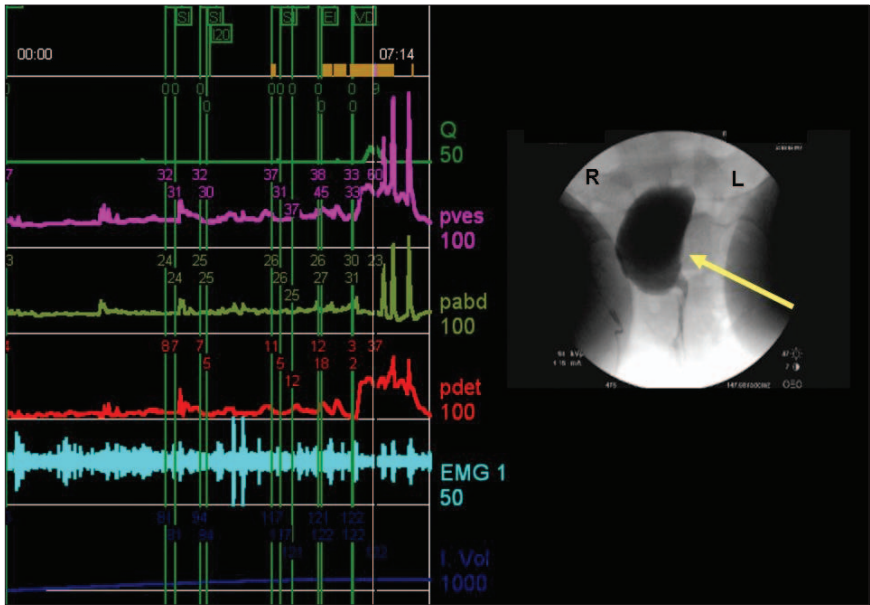

Fig. 3. Video urodynamic study tracing and imagery showing a unilateral voiding bladder contraction persisting throughout the voiding phase.

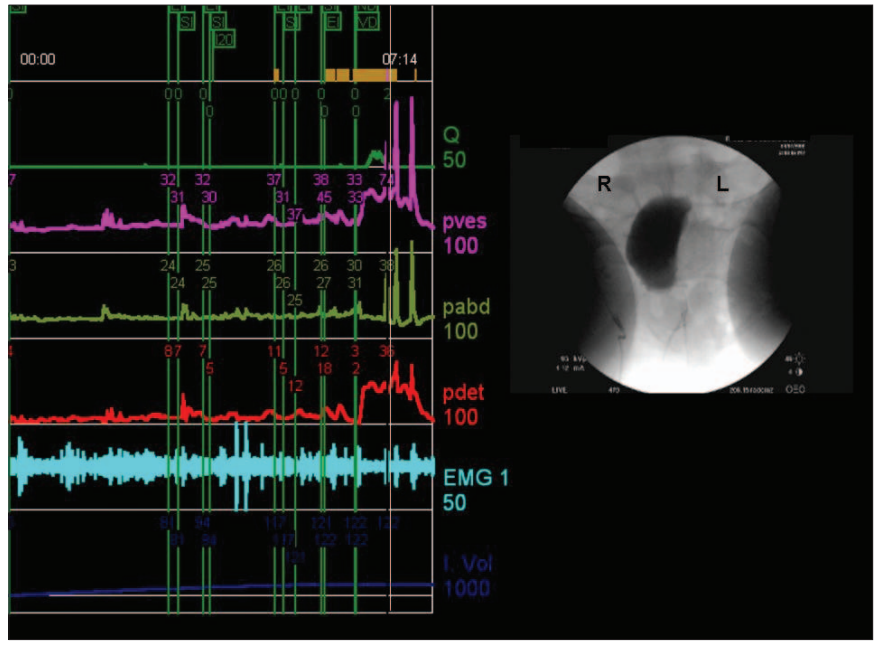

Fig. 4. Video urodynamic study tracing and imagery showing bladder asymmetry and a postvoid residual volume of $40 \mathrm{~mL}$ after cessation of voiding. pressure of $39 \mathrm{~cm} \mathrm{H} \mathrm{H}_{2} \mathrm{O}$ at maximum flow of 11 $\mathrm{mL} / \mathrm{s}$ ), and a postvoid residual urine volume of 40 $\mathrm{mL}$. Of particular interest was the finding of rightsided detrusor hemiparesis (Fig. 1, Fig. 2, Fig. 3 and Fig. 4). This study was repeated, producing the same findings. The patient underwent microsurgical transection of the tethered filum terminale 1 month later. Following surgery, the patient's right lower extremity symptoms improved. She went into urinary retention postoperatively and required intermittent self-catheterization for about 1 month before resuming her preoperative voiding patterns. VUDS were repeated 6 months after surgery to reassess the patient's bladder characteristics. The findings were similar to what was seen preoperatively. Fluoroscopy again demonstrated paralysis of the right hemibladder during voiding. She continues to have mild voiding symptoms and is voiding with a low postvoid residual volume.

\section{Discussion}

To our knowledge, this is the first report of a clinically unilateral neurologic disease process resulting in ipsilateral paralysis of the bladder. Alloussi and colleagues similarly showed that ipsilateral acontractility of the bladder was inducible using local anesthesia of the S3 sacral nerve root. ${ }^{5}$ Taken together, these findings suggest that there may be very little or no coupling between detrusor smooth muscle cell bundles crossing the midline. Thus bilateral intact innervation may be required for organized detrusor contraction of the entire bladder musculature.

From the Deptartment of Urology, Medical College of Wisconsin, Milwaukee, Wis.

This article has been peer reviewed.

Competing interests: None declared.

\section{References}

1. Bramich NJ, Brading AF. Electrical properties of smooth muscle in the guinea-pig urinary bladder. J Physiol 1996;492:185-98.

2. Mills IW, Greenland JE, McMurray G, et al. Studies of the pathophysiology of idiopathic detrusor instability: the physiological properties of the detrusor smooth muscle and its pattern of innervation. J Urol 2000;163:646-51.

3. Brading AF, Mostwin JL. Electrical and mechanical responses of guinea-pig bladder muscle to nerve stimulation. Br J Pharmacol 1998;98:1083-90.

4. Parekh AB, Brading AF, Tomita T. Studies of longitudinal tissue impedance in various smooth muscles. Prog Clin Biol Res 1990;327:375-8.

5. Alloussi SH, Lang C, Eichel R, et al. New neurophysiological aspects after passageric sacral nerve block of S3 segment. Neurourol Urodynam 2005;25:644-5.

Correspondence: Dr. Michael Guralnick, Assistant Professor, Department of Urology, Medical College of Wisconsin, 9200 W Wisconsin Ave., Milwaukee WI 53226; mguralni@mcw.edu 